\title{
Mandatory vaccination: Dentistry set to face collateral damage despite U-turn
}

The British Dental Association has welcomed the government's move to open a consultation on ending mandatory vaccination but stressed that collateral damage among the workforce remains likely, given the number of colleagues who have already made plans to the leave the service and the uncertainty now facing staff in the weeks ahead.

Under the regulations fast tracked through parliament in December, staff in both NHS and private practice risk dismissal if they are not double jabbed by April, which left 3 February as the effective deadline for a first vaccination. Over 1,000 NHS dentists left the service in the last year, and recruitment and retention problems are already endemic among both dentists and the wider team.

The service is already facing unprecedented backlogs, with over 38 million NHS dental appointments lost since the first lockdown due to the initial suspension of face-to-face care and ongoing infection control measures.

In response to a BDA survey in December, 1 in 10 high street dentists said they were not fully vaccinated, with 9\% reporting they had not had their first jab. Less than two thirds of respondents believed all dentists operating in their practices were fully vaccinated, with less than half saying their dental nurses, who are integral to the delivery of care, were fully vaccinated. Over 30\% believed dental nurses at their practices would leave as a result of the mandate.

The regulations were subject to a damning report by the House of Lords Secondary Legislation Scrutiny Committee. While an impact assessment was published at the eleventh hour, it simply extrapolated patterns of vaccine hesitancy for primary care dentistry from the wider NHS workforce, and failed to acknowledge the depth of recruitment and retention problems that already exist in the sector. The BDA is aware that internal consultations in many practices began in earnest following the passage of regulations in December, that notices have already been provided by some hesitant staff, and that significant damage has been sustained to working relationships within many close-knit dental teams.

The BDA - like all major healthcare unions - had supported the vaccine programme from the outset, but objected to this policy on the likely impact on workforce sustainability and patient access.

BDA Chair Eddie Crouch said: 'What we needed today was a clean break, instead colleagues now face confusion, and real uncertainty as to where they stand in the days and weeks ahead.

'Mandatory vaccination offers a lesson in how not to make laws. MPs and Peers rightly decried the impossibility of scrutinising fast-tracked legislation based on back-of-an-envelope calculations. This service was already haemorrhaging talent, and these rules would have pushed many dental practices over the edge.

'The late return of common sense means millions of patients may still dodge a bullet. However, it remains to be seen how many notices have already been handed in, and what the impact will be on the thousands already reconsidering their futures.'
Your choice of indemnity cover matters

\section{ce}

Reasonably priced, clear guidance and reputable advisors."

Richard Moore

Associate, North Humberside

Get your quote today

\section{bda.org/indemnity}

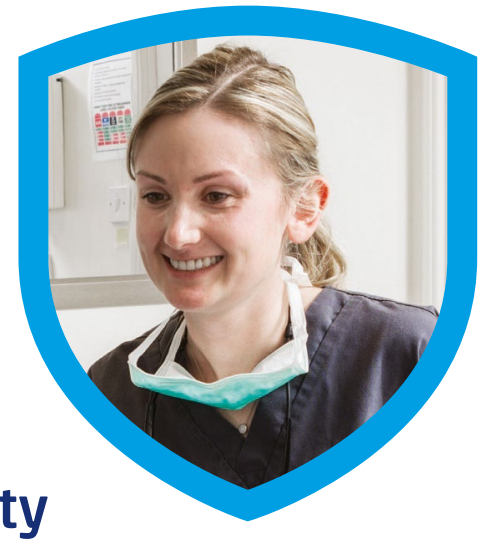

A unique service designed for dentists and dentistry 